\title{
Discussion on Origin of Birch Bark Art of Oroqen Nationality in Heilongjiang Province and Its Production Inheritance
}

\author{
Xiaoli Zhang \\ Heihe University \\ Heihe, China
}

\begin{abstract}
Birch bark culture of Oroqen Nationality in Heilongjiang Province has a long history, and birch bark culture products also play an important role in production and daily life. Birch bark technique is the development of innovation of traditional technique, which is the recreation of new technique using the traditional and original materials, endowing the new connotation. This has carried forward the culture of Oroqen Nationality while displaying the wisdom and creativity of Oroqen Nationality. This paper discusses from the aspects of birch bark art origin of Oroqen Nationality in Heilongjiang Province, the production technique of birch bark art of Oroqen Nationality in Heilongjiang Province, and birch bark art production technique inheritor of Oroqen Nationality, taking realistic question of Oroqen Nationality birch bark art as the starting point, the study on protection and inheritance of intangible cultural heritage of birch bark art as the purpose, and combining the normative research and empirical research. This is conducive to national culture inheritance, cultural diversity pursuit, and environment convergence avoidance, which can protect the national cultural heritage, enhance the understanding and recognition between nationalities.
\end{abstract}

Keywords-Heilongjiang; Oroqen Nationality; birch bark art; origin; production technique

\section{INTRODUCTION}

The first sentence of the famous Japanese song Spring of Northland is "white birch stand gracefully". Russia has the famous "Little Birch Art Troupe". Oroqen Nationality is just like a tender and beautiful flower, which is enchanting; Oroqen Nationality is also like lovely woman, who is charming and beautiful. She is a tribe that is associated with forest forever; she is an ancient nation glowing with infinite vitality; she is the creature in Xingan who creates northland hunting culture, and the nation that determines the position of birch bark with its production mode. The traditional birch bark technique continuous to develop, and there are losses, inheritance, improvements and innovation in the utility of its skills and tools in the long years. The all-round development of the society promotes the changes such as productivity progress, culture from all levels of the society, as well as the variety of art forms.

Fund Project: Annual planning project of studies in philosophy and social sciences of Heilongiang Province "Study on Protection and Inheritance of Birch Bark Art of Oroqen Nationality in Heilongiiang Province", No.: 15YSE09.

\section{ORIGIN OF BIRCH BARK ART OF OROQEN NATIONALITY IN HEILONGJIANG PROVINCE}

\section{A. Origin of White Birch Art}

Birch bark culture is an ancient cultural phenomenon with regional features. Birch bark has always been the favorite of hunting nationalities in northern China thanks to its characteristics such as easily available material, light and gentle texture, water-proof and moist insulation, relatively convenient processing, and very practical finished products. White birch grows in the cold zone and cold temperate zone of Northern Hemisphere, thereby it is called the "Sub-Arctic Birch Bark Cultural Zone". Russian Siberia and the Far East indigenous peoples, Ainu of Hokkaido, Japan, Mongolian of Mongolia as well as Sweden, Norway, Finland, etc. all have the history of birch bark culture. The birch bark culture exists in north nationalities of China such as Oroqen Nationality, Ewenki, Hezhen, Manchu, Daur, and Mongol nationality, and their ancestors form an important part of the "Sub-Arctic Birch Bark Cultural Zone". Archaeological data shows that birch bark culture has at least 3,000 years of history in the indigenous peoples of northern China. For example, the birch bark culture artifact cover, with a history of at least of more than 3,000 years, unearthed in Yinggeling Original Site of Ning' an, Heilongjiang, belongs to the Shensu People, who are the predecessors of Manchu. The twenty-odd pieces of birch bark culture objects discovered in the Inner Mongolia Zano tombs, such as the birch bark cultural bow and capsule, are the relics of Xianbei period. The birch bark cultural bucket with both embossing and clip art unearthed in Jurchen tomb of Zhongxing Town, Suibin, Heilongjiang, is a typical excavation of Jurchen, which is very valuable. At the beginning of the twentieth Century, the birch bark culture sacrificial objects are also unearthed in the stolen General Tomb of Qing Dynasty, Aihui Town, Aihui District, Heihe City. Thus, birch bark culture had been widespread in the production and life of northern hunting nationalities, especially in Manchu and their predecessors, forming the evidence that the Manchu people along the coast of Heilongjiang River had been using the birch bark cultural objects from Sushen to Jurchen, until the early years of founding of new China. For example, Oroqen Nationality people in Heihe City, Heilongjiang Province are particularly interested in using birch bark cultural objects, such 
as birch bark culture salt cans and birch bark culture cigarette boxes. In another example, some families still retain their children's fish skin satchel, snow-proof and waterproof fish skin waist belt, and the custom that coachman uses a salmon skin whip with a crisp and large sound to drive a cart. No matter the birch bark cultural objects, or the fish skin clothes, they are not confined to a certain nationality, but a more common regional cultural phenomenon. It is settled by the specific natural environment, the unique mode of production, the specific way of thinking, which has been demonstrated by the birch bark culture phenomenon at different periods.

\section{B. Inheritance and Evolution of White Birth Art}

As a result of the development of the society, imbalance appeared in the process of inheriting birch bark culture by the hunting nationalities in the north of China. Manchu, Daur nationality and other nationalities that had entered into the agricultural society needed less birch bark cultural objects; instead, the birch bark culture became more and more decorative. The use value of birch bark culture is compatible with its production and living needs, and that is the reason why the hunting or fish hunting typed birch bark culture of Oroqen Nationality, Hezhen and other nationalities is remained so complete for such a long time. The imbalance of birch bark culture development and the continuously deepening of decoration awareness demonstrate that, with the requirement of production situation, development of thinking and the increasing aesthetic taste, birch bark culture objects have gradually become the carrier of people 's aesthetic taste. It is formed in the production and living practice no matter the natural aesthetics or conscious aesthetics. Birch bark culture evolution is a long and complex process. We can only see the brief evolution outline of birth bark culture by a simple comparison of the literature and archaeological data and the realistic situation.

The above-mentioned literature describes the box car covered by birch bark culture, which can also be understood as "Zuoluozi" in Manchu, "Xierenzhu" in Oroqen Nationality language put up with birch bark culture, and all of them have the meaning of residence. In addition, there are material evidence proposed by the archeology that, the Manchu people along the coast of Heilongjiang River used the birch bark cultural objects from Sushen to Jurchen, until the founding of the New China. The data determined by carbon 14 further prove that the beginning time of hunting nationalities in northern China to use birch bark culture objects is at least 2700 earlier than that recorded in "Heilongjiang Records". We can see the brief evolution process of birth bark culture, from the original birch bark cultural barrel using zeolite to cook, to the wine sets with protruding abdominal cavity, long neck, hollow and embossing; from the simplest birch bark cultural objects to delicate jewelry box, from the initial simple and practical birch bark cultural life tools, to the magnificent birch bark culture natural texture painting arts and crafts works. It can be seen that, with the increasingly widely use of birch bark culture, birch bark culture technology is improved more and more significant, and birch bark culture function and style are also increased significantly, becoming a unique and important cultural content and art form.
As a legacy of the traditional culture of northern China, birch bark culture verifies these nationalities production in history and current situation of social life from the cultural point of view; reveals the love and understanding of nature by these nationalities who live in high latitudes from the artistic point of view, thus reflects the development of their aesthetic consciousness and aesthetic taste. It can be said, birch bark culture is a piece of valuable "living fossil" to study the history of hunting nationalities in northern China.

\section{Distribution of Birch Bark Crafts}

The Oroqen Nationality is a minority of Heilongjiang, and it is also known as "White Birth Dwelling" because of the white birth. As the first batch of intangible cultural heritage resources of the white skin technology and heritage protection, it has great research value. In China, main origins of birch bark are Xing'anling, Changbai Mountain and Zhang Guangcai Ridge. With rich forest resources, these places provide favorable conditions for the development of birch bark technique. The Heilongjiang River basin should be the main area of birch bark, which is created jointly by the aboriginal people and their ancestors of the Heilongjiang River basin. In Oroqen Nationality in Heilongjiang Province, the birch bark technique is mainly concentrated in the Xinsheng Oroqen Nationality Town, Aihui District, Heihe City, Baiyinna Oroqen Nationality Town of Huma County, 18 Station Oroqen Nationality Town of Tahe County and Xin'e Oroqen Nationality Town of Xunke County.

\section{Production TECHNIQUE OF BIRCH BARK ART OF OroQEn NATIONALITY IN HEILONGJIANG PROVINCE}

Birch bark is one of the very characteristic folk arts and crafts of Oroqen Nationality. Because most of the Oroqen Nationality locates in the North Temperate Zone, so it has rich forest resources with a large number of birch. Birch bark art has obvious features in decorative patterns and production techniques.

\section{A. Production Tools of Birch Bark Art}

It mainly includes carving knife, scalping knife, paper cutting knife, scissors, scribers, flower pistol, mallet, electric iron, painting pen, watering cans, and so on. Auxiliary equipments include engraving machine, indentation machine, cutting machine, and molding machines. Other auxiliary equipment: flattening machine, air pump, air gun, woodworking lathe and so on. Auxiliary materials: fuel, glue, adhesives and so on.

\section{B. Process Flow}

1) Material Selection: for birch bark production, the century-old high-quality white births grow in white birth forest are mainly selected, which will be distributed, peeled, cooked, cut, shaped and flatted for use according to the material selection.

2) Product Molding: blueprint formulating, cutting, threedimensional modeling and other practices, molding, cutting, peeling, sculpturing, moulding-die and color rubbing, embryo producing, and combining. 
3) Product Decoration: the main feature of birch bark process is the application of pattern design and technical skills. Main patterns of the products include continuous flower type, rolling flower type, indentation flower type, and hollow flower type; the pattern decoration techniques include carving, baking, painting, mosaic, and indentation and so on.

4) Production of Craft Painting: birch bark painting can be divided into paste mosaic and ink-style paste types according to different techniques and their production methods are also different.

Production steps of paste mosaic type can be divided into: (1). drawing segmentation draft; (2). material selection; (3). cutting; (4). pasting; (5). mounting and molding.

Production steps of ink-style paste type can be divided into: (1). material selection; (2). pasting; (3).painting; (4). mounting and molding; (5).product packaging.

After inspection of birch bark handicraft, prepare various shapes of boxed boxes, cabinets and picture frames according to different works, and integrate product characteristics, use types and geographical style into the works, print the packaging and complete the final artistic effect.

\section{Special Techniques}

1) Crystal Mosaic: This method is used for birch bark accessories, jewelry boxes, picture frames and other objects. Divide birch bark into two layers while operating. The first layer serves as the bottom lining. The second layer serves as the side for painting, on which carving will be conducted using hollow engraving method according to the pattern created by the author. And then inject the crystal paint of different hue on the hollow patterns using the needle. The crystal clear and colorful beauty will be generated upon it is solidified.

2) Hollow Chromatography: Level the birch bark, make the second layer, the third layer or the fourth layer hollow, and then smear the prepared pigment to each level. Take the scraper to conduct flat scraping on each level. Do not move to the next layer before the previous layer is dried, so that the concave pattern level will be revealed according to the works need. This work gives a simple card painting effect.

3) Spray Sticking: This method is used on the original birch bark material surface, which conducts artistic treatment on the surface of painting using chemical reagents based on the author's creative intent, upon the existing natural texture is selected. The works is of strong freehand brushwork, obvious abstract effect, strong visual impact, and powerful appeal.

4) Natural Texture Guidance: This method is to select birch sapling for key cultivation. The author follows their growth process and conducts contusion treatment on a certain layer of the birch bark according to seasonal changes. Make the adult birch bruised plus chemical treatment, to achieve the desired artistic effect, and then strip birch bark to pull layer, so as to complete the work. The work's unique beauty cannot be imitated, which is pure and nature, and will never degenerate.
5) Natural Materials Paste: This method is to make the grass root, willow root and other roots clean and dry for early modeling based on the processed birch bark material, and then make them flower-shaped, tree-shaped and other patterns after flattening. Make them attach on the birch bark plane by hot pressing. The work closes to nature with artistic effect because there is no knife mark or mosaic and other carved mark.

\section{PRoduction TECHNOLOGY INHERITOR OF OROQEN NATIONALITY BIRCH BARK ART}

Guo Baolin. In June 2007, Guo Baolin, who comes from Oroqen Nationality Town, 18th station, Daxinganling area, was awarded "Chinese Folk Culture Outstanding Inheritor" by Chinese Folk Literature and Art Association. His heritage project is "birch bark cultural boat production skills." The selection of Guo Baolin fully demonstrates that this cultural heritage is a typical cultural symbol of the Oroqen Nationality and shows that this cultural heritage is facing a gradual demise and needs to be inherited. The production of birch bark cultural boat of Oroqen Nationality has a complex process and skills. $\mathrm{Na}$ Min records in her book of "Inheritor of Birch Bark Boat Production Skills - Guo Baolin," that the production of birch bark cultural boat by Guo Baolin is divided into three parts: (1). Material Selection. The requirement for material selection is strict, for example, the birch shall be 100-year old at least, and straight, smooth, without nodules; the pinus sylvestris var used to make the ribs shall not bend and twist; this process requires both experience and patience. (2). Material Preparation. It includes the culture of birch bark peeling, chopping pinus sylvestris var; processing birch bark culture, processing camphor pine; processing both the internal and external shipboard; processing ribs; also includes assembling the boat body, setting up the boat head, fixing the boat body, accessories production, inspection and drying. (3). Repair and Maintenance. Guo Baolin has processed dozens of birch bark cultural boat in those years. His work is fine with durable quality, which has been collected by a variety of museums at home and abroad. The birch bark cultural boat of Oroqen Nationality is lighter, smoother and more beautiful in terms of modeling, compared with the canoe of the indigenous peoples of North America and the birch bark cultural boat they used, the "birch bark cultural fast horse" boat used by the Hezhen ethnic group, which is called "Never Sink until the Doomsday". In the cultural traditions of the Oroqen Nationality, they are well aware that nature is not inexhaustible, so there appears the valuable tradition of respecting nature, forest and animal protection, as well as harmony between man and nature.

Tao Dandan, female, Manchu, was born on November 22, 1978 in Aihui District, Heihe City, graduated as a junior college student from Department of Art Decoration, Harbin Normal University. She is the member of Heilongjiang Provincial Folk Literature and Art Association, member of Chinese Folk Literature and Art Association, inheritor of Heilongjiang provincial intangible culture. The original everyday appliances such as birch bark cultural boat, birch bark cultural barrel, birch bark cultural bowl, birch bark cultural hat, birch bark cultural box and so are no longer necessities for modern life. As a result, birch bark culture 
technique is about to extinct. In order to save, she inherits the unique culture of north China and retains the primitive technique, inherits and develops birch bark culture, creates the natural texture painting as well as stacking, penetrating, empting, hanging and other birch bark culture handicraft production methods for the first time, and makes innovation to design a series of birch bark cultural crafts, forming her own unique style. This has enhanced the birch bark cultural crafts their own viability and value, effectively promoted the local birch bark culture handicraft development process, and enhanced the influence nationwide. She divides birch bark painting series into three categories. The first is birch bark cultural landscape painting. To make this kind of artistic works similar to ink and landscape painting, materials of birch bark cultural landscape painting are selected from nature, so each piece is not the same with its own advantages. The second is the bark paste painting. The bark pasting craft picture is made through cutting and pasting by virtue of bark's characteristics of different colors and separability. The third is bark integrated creative painting. The landscape, figures and other works created according to the natural texture of the bark and the understanding of bark characteristics and art and using the special techniques of ironing, dying and painting, are pure white or rough and bold, which is the unique style of north China.

\section{CONCLUSION}

With the deepening of the study of Oroqen Nationality culture in recent years, especially more in-depth mining of clothing, architecture, birch bark art and other aspects, we have a more profound understanding of Oroqen Nationality national cultural changes, which has a more active role for us to further promote and protect the Oroqen Nationality national culture, as well as for the maintenance of diversified nation and social harmony. Hunting national culture is an important part of China's intangible cultural heritage, which enables more people to understand the northern hunting nation. To decorate people's lives with birch bark crafts, and feel the simple hunting culture of north China, are the responsibility and obligation granted to us by the times, and also the nation's desire and pursuit.

\section{REFERENCES}

[1] Zhang Xiaoli, Wang Yuyun. Protection and Inheritance of Oroqen Nationality Birch Bark Tea Set Art [J]. Tea In Fujian, 2016,3

[2] Zhang Xiaoli. Analysis of Birch Bark Pattern with Oroqen Ethnic Theme [J]. Popular Literature, 2011,10

[3] Zhang Xiaoli, Liu Yang. Discussion on Value Characteristics and Inheritance Strategy of Oroqen Birch Bark Art [J]. Art Panorama, 2015,11

[4] Research on protection and inheritance of oraqen birch-bark crafts of heilongjiang province OCADCE 2016 (CPCI)2016.5

[5] Zhang Xiaoli. Study on Birch Bark Crafts Protection and Inheritance of Oroqen Nationality in Heilongjiang Province [J]. Heilongjiang Basin Civilization and the Russian Far East History, Culture and Social Development Proceedings. 2016.9

[6] Tao Dandan. Birch Bark Culture and Art. [M]. Heilongjiang Fine Arts Publishing House, 2012,11. 